
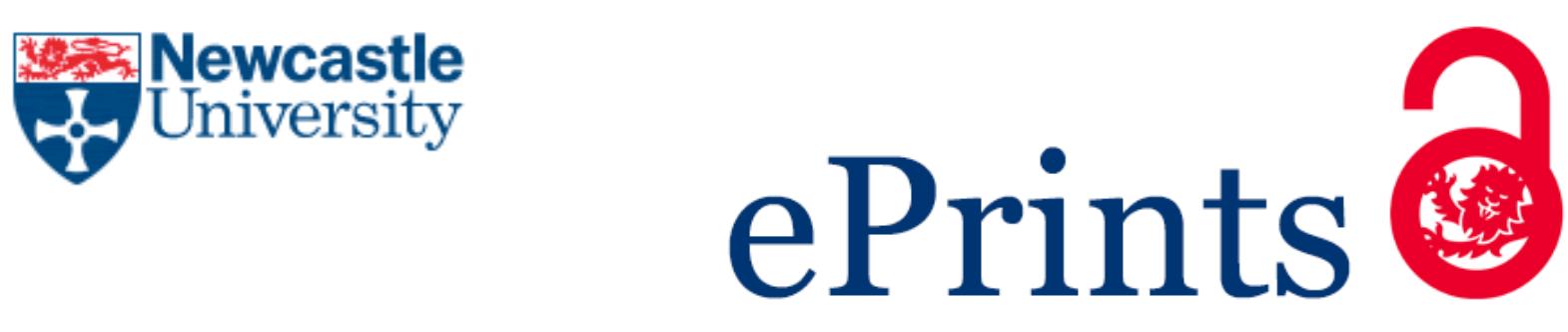

Gerrard J, Caldwell L, Kennedy A.

Green Waste and Archaeological Geophysics.

Archaeological Prospection 2015, 22(2), 139-142.

\title{
Copyright:
}

This is the peer reviewed version of the above article, which has been published in final form at http://dx.doi.org/10.1002/arp.1503. This article may be used for non-commercial purposes in accordance with Wiley Terms and Conditions for Self-Archiving.

Date deposited:

$10 / 06 / 2015$

Embargo release date:

16 February 2016

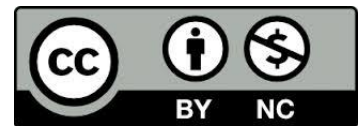

This work is licensed under a Creative Commons Attribution-NonCommercial 3.0 Unported License 


\section{Green Waste and Archaeological Geophysics}

\begin{tabular}{|r|l|}
\hline Journal: & Archaeological Prospection \\
\hline Manuscript ID: & ARP-14-0027.R1 \\
\hline Wiley - Manuscript type: & Short Report \\
\hline Date Submitted by the Author: & $17-$ Oct-2014 \\
\hline Complete List of Authors: & $\begin{array}{l}\text { Gerrard, James; Newcastle University, History, Classics and Archaeology } \\
\text { Caldwell, Liz; GeoFlo, } \\
\text { Kennedy, Alisa; ex-Newcastle University, }\end{array}$ \\
\hline Keywords: & $\begin{array}{l}\text { Green Waste, Archaeology, Magnetometry, Metal-detecting, Regulation, } \\
\text { Anthropocene }\end{array}$ \\
\hline & \\
\hline
\end{tabular}

SCHOLARONE $^{\text {m }}$
Manuscripts 


\title{
Green Waste and Archaeological Geophysics
}

\author{
Dr James Gerrard (Newcastle University), Mrs Liz Caldwell (GeoFlo) and Mrs Alisa Kennedy \\ (Newcastle University)
}

Corresponding Author: Dr James Gerrard, School of History Classics and Archaeology, Armstrong Building, Newcastle University, Newcastle Upon Tyne, UK, NE1 7RU james.gerrard@newcastle.ac.uk

\begin{abstract}
Environmental concerns, supported by regulatory frameworks, have encouraged the conversion of organic and biological waste into fertilizers and soil conditioners (so-called green waste) that are being increasingly used on arable fields. Recent work has shown that the level of ferrous contaminants within this waste can have a detrimental impact on shallow geophysical prospection methods that use the principles of magnetism. This paper highlights the negative impact of this new agricultural practice on the historic environment and calls for tighter regulation of green waste.
\end{abstract}

\section{Keywords}

Green waste; archaeology, magnetometry; metal-detecting; regulation, Anthropocene 


\title{
Green waste and archaeological geophysics
}

\author{
James Gerrard, Liz Caldwell and Alisa Kennedy
}

\begin{abstract}
Introduction
This paper aims to raise awareness of a significant and developing challenge for archaeological geophysics. The widespread use of fertilizers and soil conditioners derived from so-called 'green waste' (biodegradable and organic materials) is becoming commonplace and the diversion of this waste from landfill is widely perceived as having numerous environmental benefits (EC 2010). Unfortunately these macro-scale environmental benefits come at a cost to the historic environment on a micro-scale.
\end{abstract}

\section{A virtuous circle?}

The Landfill Directive (EU, 1999) stipulates that EU member states had to agree a series of binding reductions in the quantity of biodegradable waste being landfilled. Taking 1995 levels as a base line, obligatory reductions of $25 \%$ over five years, $50 \%$ over eight years and $65 \%$ over fifteen years (EU, 1999: 5.2) were imposed. The UK government had already developed a policy to tackle this issue by introducing a landfill tax in 1996, which established a charge for every tonne of waste sent to landfill (UK, 1996).

The environmental justifications for these policy changes are well known and reducing the quantity of biodegradable and organic waste was (and remains) a priority (EC, 2010). Some $90 \%$ of municipal solid waste (MSW) could be formed of these biodegradable materials (Slater and Frederickson, 2001: 368-69) and reducing this quantity minimizes emissions from the decomposition of organic waste and saves space in landfill sites (Lou and Nair: 2009). To achieve this goal MSW is now separated into different waste streams with animal by-products subjected to anaerobic digestion, which produces energy (Slater and Frederickson, 2001: 25). The residues from this process can be incorporated into composted garden rubbish or 'green waste', which can be marketed as a fertilizer providing the product conforms to BSI PAS100 and BSI PAS110.

The production of these composts offers a seemingly virtuous circle (EU, 2010). Councils can use composting to escape punitive landfill taxes and for the recycling industry composting and 
anaerobic digestion offers a means of creating saleable products (energy and fertilizer).

Farmers benefit by gaining access to compost that can be used to fertilize their fields at a time when agricultural fertilizers are increasing in price (WRAP, 2013: 9-10). For environmentalists the ecological benefits in terms of reductions in greenhouse gases and other forms of pollution are clear. There appear to be no downsides. However, the impact of green waste deposition on the historic environment has received scant attention.

\section{Geophysics and green waste}

Between 2009 and 2014 the immediate hinterland of a Roman villa in Somerset was surveyed using magnetometry (Caldwell, 2009). The surveys identified an extensive but hitherto unknown settlement around the Roman villa. As work progressed to define the extent of this settlement it became apparent that these fields offered an exemplary case study for the investigation of the impact of green waste on archaeological prospection using magnetometers.

Just prior to the geophysical survey being undertaken in 2011 the landowner spread one of the fields (Danscombe) with 30t of green waste a hectare (Figs 1 and 2). The field is small (3ha) but it was apparent that the green waste contained a significant quantity of inorganic contaminants, including batteries, pieces of metal cans and other items. Clearly these objects would have an impact on the survey results. Nevertheless the survey went ahead using a Bartington Grad 601-2 fluxgate gradiometer. Readings were logged every $0.25 \mathrm{~m}$ along northsouth traverses set $1 \mathrm{~m}$ apart in a zig-zag fashion and the data was processed in Geoplot 3.00v. Comparison of the resulting geophysical plot with the surveys in the surrounding fields highlights the poor quality of the data collected from Danscombe. Interference is generally in the range of $5-15 n T$, with a scatter of anomalies in the $>30 \mathrm{nT}$ range. Archaeological anomalies are visible but comparison with the fields to the north and east demonstrates that subtler geophysical anomalies have probably been masked by the green waste.

To test the longer term impact of green waste the field was resurveyed in 2013 using the same methodology. It was hoped that the data might be of a higher quality than the original survey. Some new archaeological anomalies (in the range of $2-4 \mathrm{nT}$ ) were identified but the interference was still clearly visible, with little diminution over the intervening period. 
The cause of the interference would appear to be mainly the product of metal contaminants, which are typified by 'iron spikes'. The BSI PAS 100 specification requires waste destined for composting to be screened to remove physical contaminants such as 'glass, metal, plastic and other non-stone fragments' but such contaminants are not completely excluded. Up to $0.25 \%$ of a composted product may be formed from such materials (BSI PAS 100). This seems like a small quantity but assuming the compost spread on Danscombe was within the specification, then the $90 \mathrm{t}$ of green waste would have included $225 \mathrm{kgs}$ of contaminants. These contaminants (including non-magnetic materials) will cumulatively increase with successive applications of green waste to fields.

The survey of Danscombe presents an alarming scenario: over time large swathes of arable land may be blanketed with green waste with a significant impact on our most commonly used method of geophysical prospection. In regions such as southern Somerset, where magnetometry is an essential means of archaeological prospection, the implications of this scenario are catastrophic.

\section{The scale of green waste usage on arable land}

In 2009 the EU composted 45Mt of waste and much of this waste ends up on arable land. Definite statistics are difficult to reconstruct but Germany spreads perhaps 2.5Mt annually on arable land (Eurostat, 2014, Table 1; ECN, 2014). Statistical data for England indicates that composting rates leapt from just over $0.25 \mathrm{Mt}$ in $1996 / 7$ to over $3.5 \mathrm{Mt}$ in 2009/10 (ENV18, 2013). If half of the latter figure was spread on arable land at the rates used in Somerset then 66,000 ha would be impacted annually.

Anecdotal evidence also allows an idea of the scale of green waste production in the UK. In 2007 'The Land Network' supplied sixteen farms with $0.1 \mathrm{Mt}$ tonnes of green waste (Butterworth, 2007). In 2009 over three hundred facilities were thought to be involved in the composting of waste (Song et al., 2009: 2130) and Veolia produces over 0.2Mt of green waste compost annually (Veolia, 2014). However, perhaps the best evidence for the widespread use of green waste comes from the metal detecting community.

Online forums dedicated to metal detecting abound with discussions and images of metal contaminants recovered by metal detectorists (MDF, 2014). This has caused such problems that detectorists have only called for green waste to be banned and lobbied the UK parliament (Wells, 2012). These widespread difficulties demonstrate the challenges that will increasingly 
confront archaeologists carrying out geophysical surveys and controlled metal-detector surveys on land treated with green waste.

\section{Green waste and its implications for policy and practice}

In 2010 the European Commission (2010: 7.2.5) suggested that:

Member States should promote the production and use of compost from "clean" biowaste. They should pro-actively support the wide up-take of this material by endusers. This would improve resource efficiency by partially replacing non-renewable mineral fertilizer as well as by maintaining the quality of EU soils. Member States should proactively participate in the definition of quality criteria... and support their application to accelerate market growth.

Green waste is here to stay. The macro-scale environmental and economic benefits of processing waste into a product that can be beneficially spread on the land will outweigh many other considerations. This scenario, in which mechanized industrial farming spreads waste and its contaminants across arable land in large and seasonally cumulative quantities, is already here and represents another manifestation of what is increasingly being termed the Anthropocene (Steffen et al., 2011).

How should archaeologists in the UK, EU and further afield respond to the challenge that this phenomenon will increasingly pose to archaeological prospection techniques based on the principles of magnetism? Banning green waste would be one solution (Wells, 2012) but is unrealistic. Nation states and communities need to process and reuse waste and this imperative is unlikely to be derailed by small pressure groups.

A more constructive stance would be for those concerned by the spread of green waste and its contaminants to push at national and supra-national levels for more stringent regulation of green waste and its physical contaminants coupled with the robust enforcement of these regulations. Additional clauses could be drafted into existing regulatory frameworks that take into account the impact of green waste on the historic environment. In the UK fields treated with green waste could be recorded on the local Historic Environment Records. 
Changing how green waste is regulated would not be easy or straightforward. Further research on the spread and impact of green waste, and further geophysical work to assess its impact, would be necessary. Nevertheless, this is work that should be considered before one of the most important archaeological prospection techniques is emasculated.

\section{References}

Butterworth B. 2007. How recycling green waste benefits farming. The Telegraph, 10 July 2007, http://www.telegraph.co.uk/earth/3299984/How-recycling-green-waste-benefits-farming.html (accessed 6/3/2014).

BSI PAS100. Specification for Composted Material. http://www.wrap.org.uk/content/bsi-pas-100compost-specification (accessed 18/12/2013).

BSI PAS110. Specification for whole digestate, separated liquor and separated fibre derived from anaerobic digestion of source-segregated biodegradable materials.

http://www.wrap.org.uk/content/bsi-pas-110-specification-digestate (accessed 18/12/2013).

Caldwell L. 2009. Lufton Villa, Yeovil, Somerset: Geophysical Survey, March 2009. Unpublished Report SSARG/GS1003.

EC 2010. Communication from the Commission to the Council and European Parliament on future steps in bio-waste management in the European Union. $\operatorname{COM(2010)235Final.~}$

http://ec.europa.eu/environment/waste/compost/pdf/com biowaste.pdf (accessed 6/3/2014).

ECN 2014. European Compost Network: Country Report Germany.

http://www.compostnetwork.info/germany.html (accessed 3/4/2014).

ENV18 2013 ENV18 - Local Authority Collected Waste: annual results tables.

https://www.gov.uk/government/statistical-data-sets/env18-local-authority-collected-waste-annualresults-tables (date accessed 18/12/2013).

Environment Agency 2013. Additional guidance for trials for the recovery to land for agricultural benefit of compost-like outputs from the treatment of mixed municipal solid waste EPR 6.15.

http://cdn.environment-agency.gov.uk/geho0512bwls-e-e.pdf (accessed 18/12/2013). 
EU 1999. Council Directive 1999/31/EC of 26 April 1999 on the landfill of waste. http://eurlex.europa.eu/LexUriServ/LexUriServ.do?uri=OJ:L:1999:182:0001:0019:EN:PDF (accessed 19/12/13).

Eurostat 2014. Municipal Waste Statistics.

http://epp.eurostat.ec.europa.eu/statistics explained/index.php/Municipal waste statistics (accessed 3/4/2014).

Lou, X. and Nair, J. 2009. The impact of landfilling and composting on greenhouse gas emissions.

Bioresource Technology 100: 3792-3798. DOI: 10.1016/j.biortech.2008.12.006

MDF 2014. Green waste. Metal Detecting Forum.

http://www.metaldetectingforum.co.uk/viewtopic.php?f=10andt=18729 (accessed 24/4/2014).

Slater R. and Frederickson J. 2001. Composting municipal waste in the UK: some lessons from Europe.

Resources, Conservation and Recycling 25: 359-374. DOI: 10.1016/S0921-3449(01)00071-4

Song, J. Murphy R., Narayan, R. and Davies G. 2009. Biodegradable and compostable alternatives to plastics. Philosophical Transactions of the Royal Society B 364: 2127-2139. DOI: 10.1098/rstb.2008.0289

Steffen, W., Grinevald, J., Crutzen, P. and McNeill, J. 2011 The Anthropocene: conceptual and historical perspectives. Philosophical Transactions of the Royal Society a 369, 842-867. DOI:

10.1098/rsta.2010.0327

UK 1996. The Landfill Regulations 1996. http://www.legislation.gov.uk/uksi/1996/1527/contents/made (accessed 19/12/13).

Veolia 2014. Veolia: Composting Facilities.

http://www.veoliaenvironmentalservices.co.uk/Main/Facilities/Composting/ (accessed 13/2/2014).

Wells, J. 2012. Waste: not wanted. Digging Deeper 9: 8-9.

WRAP 2013. Using Compost in Agriculture and Field Horticulture.

http://www.wrap.org.uk/sites/files/wrap/AgCIP1.pdf (accessed 19/12/2013). 
Figure Captions

Fig 1 The geophysical survey at Lufton.

Fig 2 The interference caused by the green waste in Danscombe (left) can be clearly contrasted with the untreated field to the right. 


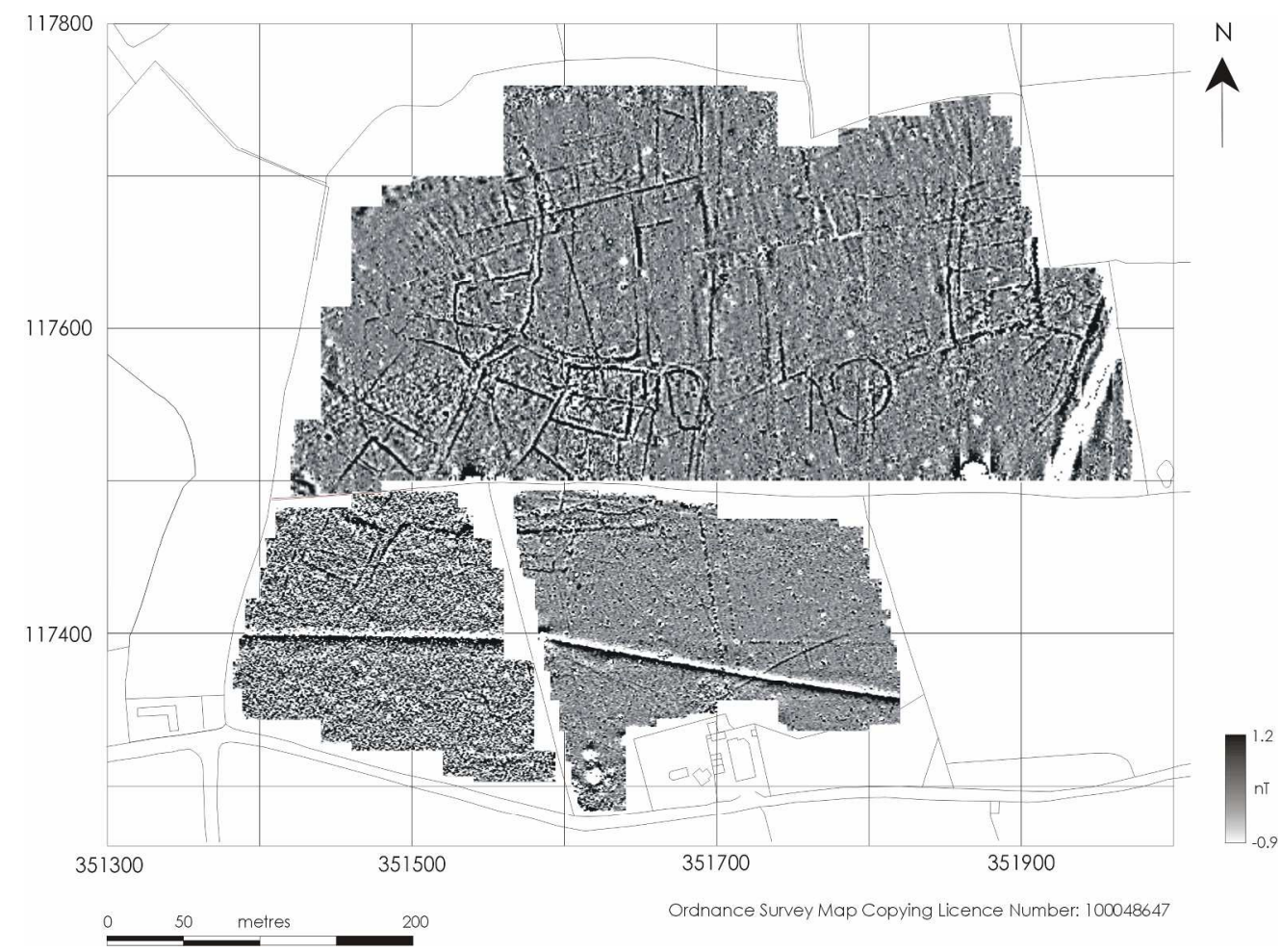

The geophysical survey at Lufton. The south-western field is 'Danscombe' and the interference caused by the geophysical survey can be clearly seen. 


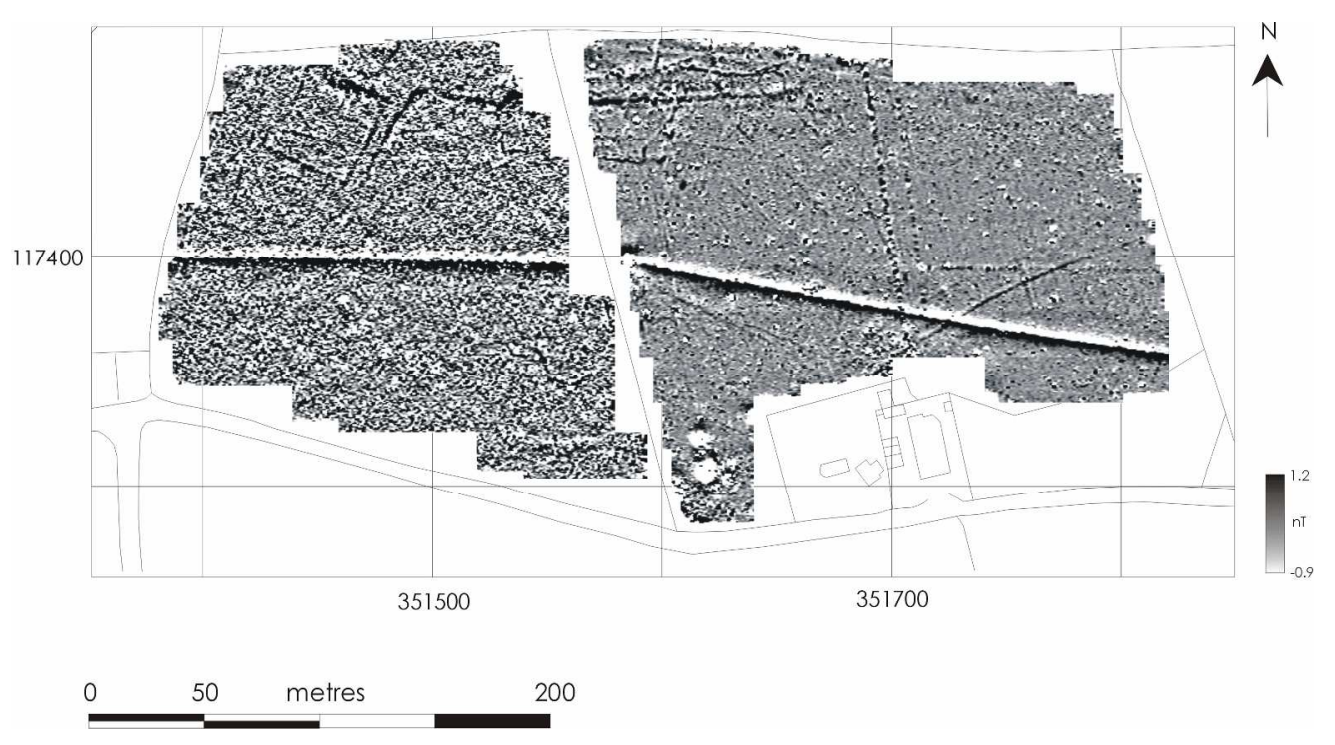

Fig 2 The interference caused by the green waste in Danscombe (left) can be clearly contrasted with the untreated field to the right. 